\title{
Saf Karaçam Meşcerelerinde Yaprak Alan İndeksi ile Meşcere Parametreleri Arasındaki İlişkilerin Modellenmesi
}

\author{
${ }^{1}$ Sinan BULUT, Alkan GÜNLÜ ${ }^{*}$, Mücahit Y1lmaz SÖNMEZ ${ }^{2}$ \\ ${ }^{1}$ Çankırı Karatekin Üniversitesi, Orman Fakültesi, Orman Mühendisliği Bölümü,18200, Çankırı \\ ${ }^{2}$ Çankırı Karatekin Üniversitesi, Fen Bilimleri Enstitüsü, Orman Mühendisliği Anabilim Dalı, 18200, Çankırı
}

Öz

$\mathrm{Bu}$ çalışmada, saf karaçam meşcerelerinde yaprak alan indeksi (YAİ) ile bazı meşcere parametreleri (meşcere hacmi, meşcere göğüs yüzeyi, meşcere ağaç sayısı, meşcere orta çapı ve bonitet endeksi) arasındaki ilişkiler çoğul regresyon analizi ile modellenmiştir. $\mathrm{Bu}$ amaçla, 30 adet örnek alanda klasik envanter ölçümleri Ekim ayında yapılmış ve her bir örnek alanın meşcere parametreleri hesaplanmıştır. Bununla birlikte, Haziran-Aralık aylarına ilişkin çekilmiş yarı-küresel fotoğraflar yardımıyla her bir örnek alanın YAİ değerleri yedi ay için hesaplanmıştır. Modellere ait performans kriter sonuçlarına göre en yüksek başarı Temmuz $\left(\mathrm{R}^{2}=0,64\right.$, Hataların Ortalama Kare Kökü $(H O K K)=0,262)$, Ekim $\left(\mathrm{R}^{2}=0,64\right.$, HOKK=0,158) ve ayların ortalama YAİ değerlerinin yer aldığı modellerde $\left(\mathrm{R}^{2}=0,64\right.$, HOKK=0,176) bulunmuştur. Poudel ve Cao (2013) tarafından önerilen rölatif sıralama yöntemi kullanıldığında Ekim ayı için (Sıralama değeri=3,945) üretilen modelin daha kullanılabilir olduğu belirlenmiştir. Modellere ait bütün performans kriterleri değerlendirildiğinde en iyi sonucun meşcere parametrelerinin ölçüldüğü ay olan Ekim ayında olduğu tespit edilmiştir.

Anahtar Kelimeler: Yaprak alan indeksi, meşcere parametreleri, regresyon analizi, saf karaçam meşcereleri.

\section{Modeling The Relationships between Leaf Area Index and Stand Parameters in Pure Crimean Stands}

\begin{abstract}
The relationships between leaf area index and some stand parameters (stand volume, stand basal area, number of trees, the quadradic mean diameter and site index) were modeled by multiple regression analysis in pure Crimean pine stands in the case study area. For this purpose, classical forest inventory measurements were carried out in 30 sample plots in October and stand parameters of each sample plot were calculated. In addition, leaf area index values of each sample plot were calculated for seven months with the help of hemispherical photographs taken in each sample plots from June to December. According to the performance criterion results of the models, the highest success was found in July $\left(R^{2}=0,64\right.$, Root Mean Square Error (RMSE) $\left.=0,262\right)$, October $\left(R^{2}=0,64\right.$, RMSE $=0,158)$ and the model with the average LAI values of the months $\left(\mathrm{R}^{2}=0,64\right.$, RMSE $\left.=0,176\right)$. When using the relative ranking method proposed by Poudel and Cao (2013), it was determined that the model produced for the month of October (Ranking value=3,945) was more usable than the other models. When all the performance criteria of the models were evaluated, it was seen that the best result was obtained in October.
\end{abstract}

Keywords: Leaf area index, stand parameters, regression analysis, pure Crimean pine stands. 


\section{Giriş}

Yaprak alan indeksi (YAİ) birim alana düşen ve aktif olarak fotosentez yapmakta olan yaprak alanı miktarıdır. Yapraklar fotosentezin gerçekleştiği dolayısı ile karbondioksit ve suyun güneş 1şınları ile karbonhidrat ve oksijene dönüştüğü bitki organlarıdır. Büyüme ve verimlilik ile ilgili önemli bir gösterge olan YAİ, meşcere kapalılığının da etkin bir göstergesidir. Fırtına, kar ve rüzgâr kaynaklı devrilmeler, kuraklık gibi doğal afetler ve planlama uygulamaları sonucu YAI'deki herhangi bir değişiklik meşcerelerin üretkenliğini doğrudan etkilemektedir. Bir meşcerenin yüksek YAİ değerine sahip olması yetişme ortamı verimliliğinin iyi olduğunu göstermektedir (Vose and Allen, 1988). Bu nedenle meşcere parametrelerinin modellenmesinde yaygın olarak kullanılmakta ve özellikle artım, büyüme ve hacim gibi meşcere özellikleri ile yüksek oranda ilişkiler göstermektedir. Uzun dönem izlenmesi ile orman ekosistem verimliliği ve iklim dinamiklerindeki değişim daha iyi bir şekilde yorumlanabilmektedir (Kara vd. 2011, Chianucci vd., 2015, Günlü vd., 2017).

YAİ'nin belirlenmesinde doğrudan ve dolaylı olmak üzere iki yöntem kullanılmaktadır. Doğrudan yöntem döküm toplama ve yaprak kapanları ile birim alandaki yaprak miktarının belirlenmesi şeklinde uygulanmaktadır. Bu metot fazla emek isteyen ve zaman alıcı bir yöntemdir. Dolaylı yöntem ise optik algılayıcılar (yarı-küresel fotoğraf) ve geliştirilen modeller kullanılarak YAİ'nin tahmin edilmesi şeklindedir. $\mathrm{Bu}$ metot ise büyük alanlar için uygulanması kolay, zaman ve maliyet açısından da bir o kadar avantajlıdır (Chen vd., 1997, Jonckheere vd., 2004). YAİ'nın belirlenmesinde yarı-küresel fotoğraflar yaygın bir şekilde kullanılmaktadır (Mason vd., 2012, Ercanlı vd., 2018).

Yapılan birçok çalışmada YAİ ile meşcere parametreleri arasında önemli düzeyde ilişkilerin olduğu görülmüştür (Turner vd., 2000, Jeleska, 2004, Madugundu vd., 2008, Khosravi vd., 2012, Sidabras ve Augustaitis, 2015). Bu çalışmada meşcere orta çapı, bonitet endeksi, meşcere ağaç sayısı, meşcere göğüs yüzeyi ve meşcere hacmi ile aylara ilişkin (Haziran-Aralık) YAİ değerleri arasındaki ilişkiler incelenmiştir. Ayrıca Haziran-Aralık aylarına ait YAİ ve ortalama YAİ, meşcere parametreleri kullanılarak çoklu regresyon analizi ile modellenmiştir.

\section{Materyal ve Metot}

\section{1. Çalışma Alanı}

Bu çalışma, Ankara Orman Bölge Müdürlüğü, Ilgaz Orman İşletme Müdürlüğüne bağlı Yenice ve Üçpınar Orman İşletme Şeflikleri sınırları içerisinde yayılış gösteren saf karaçam meşcerelerinde gerçekleştirilmiştir (Şekil 1). Çalışma alanının iklim tipi Karadeniz iklim tipi şeklindedir. Çalışma alanı yükseltisi 1.300-1.400 m arasında olup, yıllık ortalama yağış 477 mm'dir (Anonim, 2009, Ercanlı vd., 2018). 


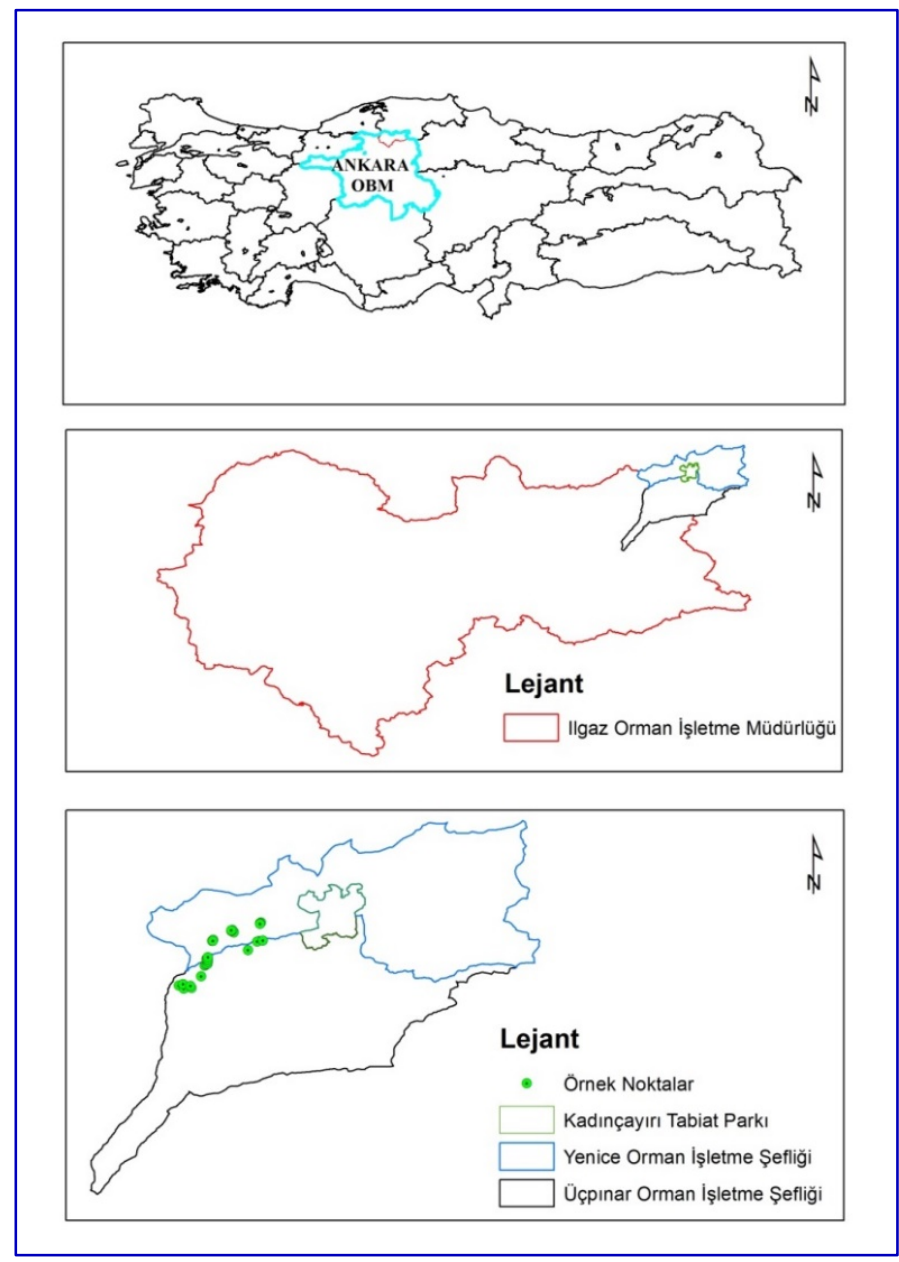

Şekil 1. Çalışma alanının konumu ve örnek alanlar.

\subsection{Materyal}

Farklı gelişim çağları, kapalılık sınıfları ve yetişme ortamı verim gücüne göre belirlenen 30 örnek alanda klasik envanter ölçümleri gerçekleştirilerek meşcere parametreleri elde edilmiştir. Ayrıca her bir örnek alanın yaprak alan indeksini (YAİ) belirlemek için çekilen yarı-küresel fotoğraflar, bu çalışmada materyal olarak kullanılmıştır. YAİ (aylara ölçekte) ve meşcere parametrelerine ilişkin tanımlayıcı istatistiksel değerler Tablo 1 'de verilmiştir.

Tablo 1. Meşcere parametreleri ve yaprak alan indeksine ilişkin tanımlayıcı istatistiki değerleri.

\begin{tabular}{|c|c|c|c|c|c|c|}
\hline$\overline{\text { Değişken }}$ & $\overline{\text { Örnek Sayısı }}$ & Minimum & Maksimum & Ortalama & Standart Sapma & $\begin{array}{l}\text { Varyasyon } \\
\text { Katsayısi } \\
(\%)\end{array}$ \\
\hline V (m³/ha) & 30 & 143 & 923 & 426,40 & 202,667 & 47,53 \\
\hline $\mathrm{G}\left(\mathrm{m}^{2} / \mathrm{ha}\right)$ & 30 & 18 & 81 & 42,80 & 16,346 & 38,19 \\
\hline $\mathrm{N}$ (adet/ha) & 30 & 150 & 2050 & 780,60 & 541,719 & 69,40 \\
\hline $\operatorname{dg}(\mathrm{cm})$ & 30 & 15 & 51 & 31,17 & 10,706 & 34,35 \\
\hline $\mathrm{BE}(\mathrm{m})$ & 30 & 13 & 34 & 26,47 & 5,022 & 18,97 \\
\hline Haziran YAİ $\left(\mathrm{m}^{2} \mathrm{~m}^{-2}\right)$ & 30 & 0,540 & 2,160 & 1,312 & 0,402 & 30,64 \\
\hline Temmuz YAİ $\left(\mathrm{m}^{2} \mathrm{~m}^{-2}\right)$ & 30 & 0,470 & 2,140 & 1,316 & 0,442 & 33,59 \\
\hline Ağustos YAİ $\left(\mathrm{m}^{2} \mathrm{~m}^{-2}\right)$ & 30 & 0,590 & 2,060 & 1,260 & 0,371 & 29,44 \\
\hline Eylül YAİ $\left(\mathrm{m}^{2} \mathrm{~m}^{-2}\right)$ & 30 & 0,560 & 1,910 & 1,161 & 0,331 & 28,51 \\
\hline Ekim YAİ $\left(\mathrm{m}^{2} \mathrm{~m}^{-2}\right)$ & 30 & 0,450 & 1,430 & 0,984 & 0,268 & 27,24 \\
\hline $\operatorname{Kasım}$ YAİ $\left(\mathrm{m}^{2} \mathrm{~m}^{-2}\right)$ & 30 & 0,450 & 1,300 & 0,909 & 0,243 & 26,73 \\
\hline Aralık YAI $\left(\mathrm{m}^{2} \mathrm{~m}^{-2}\right)$ & 30 & 0,380 & 1,130 & 0,825 & 0,196 & 23,76 \\
\hline Ortalama YAİ $\left(\mathrm{m}^{2} \mathrm{~m}^{-2}\right)$ & 30 & 0,557 & 1,670 & 1,128 & 0,300 & 26,60 \\
\hline
\end{tabular}

V: meşcere hacmi, GY: meşcere göğüs yüzeyi, N: meşcere ağaç sayısı, dg: meşcere orta çapı, BE: bonitet endeksi, YAİ: Yaprak alan indeksi 


\subsection{Metot}

Bu çalışmada klasik envanter ölçümleri 2020 yılı Ekim ayında gerçekleştirilmiştir. Bu kapsamda meşcerelerin kapalılığına göre örnek alanların büyüklüğü belirlenmiştir. Örnek alan büyüklükleri $400 \mathrm{~m}^{2}$ (3 kapalı meşcerelerde), $600 \mathrm{~m}^{2}$ (2 kapalı meşcerelerde) ve $800 \mathrm{~m}^{2}$ (1 kapalı meşcerelerde) olmak üzere üç farklı büyüklükte alınmıştır. Her bir örnek alanda örnek alan içerisine giren ve göğüs yüksekliği çapı $8 \mathrm{~cm}$ ve üzerindeki ağaçların çapları ölçülmüştür. Bununla birlikte her bir alanın bonitet endeks değerinin hesaplanması amacıyla hektarda 100 ağaç yöntemi kullanılarak örnek alan içerisinde yaş ve üst boy ölçümü gerçekleştirilmiştir. Her bir örnek alandan elde edilen veriler kullanılarak meşcere orta çapı $\left(\mathrm{d}_{\mathrm{g}}\right)$, bonitet endeksi $(\mathrm{BE})$, meşcere ağaç sayısı $(\mathrm{N})$, meşcere göğüs yüzeyi $(\mathrm{G})$ ve meşcere hacmi $(\mathrm{V})$ örnek alan bazında hesaplanmıştır. Daha sonra N, G ve V değerleri hektara çevirme katsayısı ile çarpılarak hektardaki değerler hesaplanmıştır. Alınan örnek alanların hacimlerinin hesaplanmasında; Ercanlı ve Bolat (2020) tarafindan Ankara Orman Bölge Müdürlüğü sınırları içerisinde yayılış gösteren saf karaçam meşcereleri için geliştirilmiş olan çift girişli ağaç hacim denklemi (Denklem 1) kullanılmıştır. Bu denklemin kullanılabilmesi için örnek alanlardaki boyları ölçülmeyen ağaçların boylarının hesaplanması için geliştirilen boy denklemi (Denklem 2) kullanılmıştır. Böylece örnek alanlarda boyları ölçülmeyen her bir ağacın boyları hesaplanmıştır. Örnek alanda yer alan ağaçların çap ve boy değerleri denklemde yerine konularak her bir ağacın dikili gövde hacmi, her bir ağacın hacmi toplanarak örnek alanın hacmi hesaplanmıştır. Örnek alana ilişkin elde edilen hacim miktarı ile örnek alan büyüklüğ̈̈ne göre belirlenen hektara çevirme katsayısı çarpılarak hektardaki hacim değerleri hesaplanmıştır.

$V=0.000097 * d_{1.3}^{1.740878} * h^{1.005521}$

$h=1.3+\left(5.47 * B E^{0.547}\right) *\left(1-e^{-0.042\left(\frac{N}{G}\right)^{-0.360} * d_{1.3}}\right)^{0.648}$

Denklemlerde V: ağacın gövde hacmini $\left(\mathrm{m}^{3}\right)$, h: ağacın boyunu $(\mathrm{m}), \mathrm{d}_{1.3}$ : ağacın göğüs çapını $(\mathrm{cm}), \mathrm{BE}$ : örnek alanın bonitet endeks değerini (m), N: örnek alanın hektardaki ağaç sayısını, G: örnek alanın hektardaki göğüs yüzeyini $\left(\mathrm{m}^{2}\right)$ ifade etmektedir.

YAİ'nin belirlenmesi için her örnek alanda 5 adet yarı küresel fotoğraf alınarak dijital ortama aktarılmıştır. Örnek alanlara ilişkin fotoğraflar her bir ay (ayın son günlerinde) için ayrı ayrı çekilmiştir. Ardından bu fotoğraflar Hemiwiev, H. version: 2.1 SR4 yazılımı kullanılarak analiz edilmiştir. Analiz sonucu elde edilen değerlerin ortalaması alınarak, her bir örnek alana ilişkin YAİ değeri her bir ay için (Haziran-Aralık) hesaplanmıştır (Şekil 2).

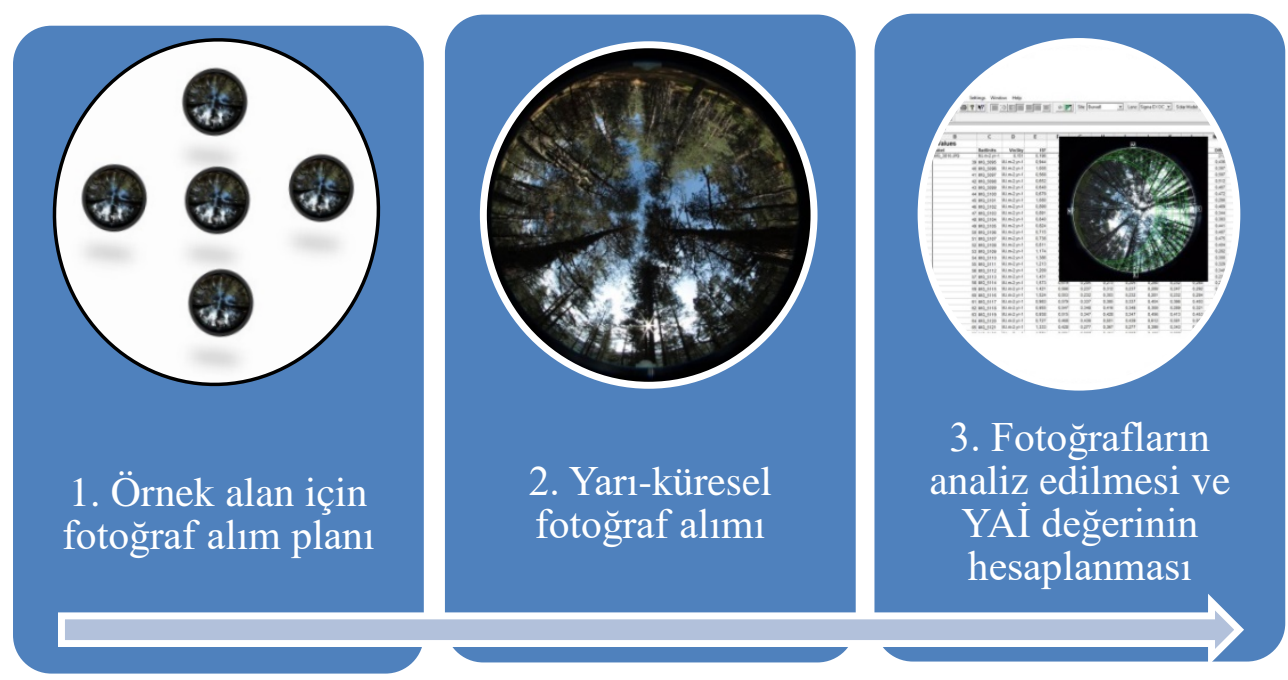

Şekil 2. YAİ değerlerinin hesaplanması.

\section{1. İstatistiksel Analiz}

Çalışmada istatistiksel analiz olarak korelasyon (partial) ve çoğul regresyon analizi kullanılmıştır. İstatistiksel analizlerin yapılmasında SPSS 15.0 istatistik paket programından yararlanılmıştır. 
YAİ ve meşcere parametreleri arasındaki ilişkilerin modellenmesinde çoğul regresyon analizi kullanılmıştır. Model yapısı ve kullanılan parametreler aşağıda yer almaktadır.

Model: YA $\dot{I}=\beta_{0}+\beta_{1} \cdot X_{1}+\beta_{2} \cdot X_{2+\ldots \ldots \ldots .+} \beta_{n} \cdot X_{n}+\varepsilon$

Model 'de YAİ (Yaprak Alan İndeksi) bağımlı değişken olarak seçilmiştir. Bağımsız değişkenler ise verilen denklemde $\mathrm{X}_{1}, \mathrm{X}_{2}, \ldots, \mathrm{X}_{\mathrm{n}}$ olmak üzere meşcere parametreleri olmuştur.

\subsection{Model Değerlendirme Kriterleri}

Çalışmada modellerin başarı ölçütleri olarak; korelasyon katsayısı (r), belirtme katsayısı $\left(\mathrm{R}^{2}\right)$ ve Hataların Ortalama Kare Kökü (HOKK) kullanılmıştır. Değerlendirme kriterlerinin (r, ve HOKK) tamamını dikkate alarak en başarılı modeli bulmak için sıralama yöntemi kullanılmıştır (Denklem 4). Bu yöntem birden fazla başarı kriteri dikkate alınarak daha tutarlı bir karşılaştırma yapılmasına olanak sağlamaktadır.

$R_{i}=1+\left(\frac{(m-1) x\left(S_{i}-S_{\min }\right)}{S_{\operatorname{mak}}-S_{\min }}\right)$

Denklemde $R_{i}$ yöntem sıralaması (i=1, $2, \ldots, m$ ), $S_{i}$ yöntem tarafından üretilen performans değeri, $S_{\min }$ ve $S_{\text {mak }}$ yöntem değerlerinin en düşük ve en yüksek değerleridir (Poudel ve Cao, 2013).

\section{Bulgular ve Tartışma}

Yaprak alan indeksi (YAI) ile meşcere parametreleri (meşcere hacmi, meşcere göğüs yüzeyi, meşcere ağaç sayısı, meşcere orta çapı ve bonitet indeksi) arasındaki ilişkiler belirlenmiştir (Tablo 2). Tablo 2 incelendiğinde ortalama YAİ ile meşcere parametrelerinden meşcere hacmi $(\mathrm{V})$, meşcere göğüs yüzeyi $(\mathrm{G})$, meşcere ağaç sayısı (N) ve bonitet endeksi (BE) arasında pozitif yönde anlamlı ilişkilerin olduğu görülmüştür. Buna karşıı ortalama YAİ ile meşcere orta çapı $\left(\mathrm{d}_{\mathrm{g}}\right)$ arasında ise negatif yönde ilişkilerin olduğu görülmüştür. 
Tablo 2. Yaprak alan indeksi ile meșcere parametreleri arasındaki ilișkilerin yönünü ve derecesini gösteren Pearson korelasyon katsayıları.

\begin{tabular}{|c|c|c|c|c|c|c|c|c|c|c|c|c|c|}
\hline Değişken & $\overline{\mathrm{V}}$ & $\mathbf{G}$ & $\mathbf{N}$ & $\overline{d_{g}}$ & $\overline{B E}$ & Haziran & Temmuz & Ağustos & Eylül & Ekim & Kasım & Aralık & Ortalame \\
\hline $\mathbf{V}$ & 1 & $0,952^{* *}$ & $-0,119$ & $0,505^{* *}$ & 0,178 & $-0,003$ & $0,398^{*}$ & 0,256 & 0,298 & 0,348 & $0,392^{*}$ & $0,428^{*}$ & 0,278 \\
\hline G & & 1 & 0,145 & 0,289 & 0,208 & 0,150 & $0,521^{* *}$ & $0,431^{*}$ & $0,470^{* *}$ & $0,514^{* *}$ & $0,552^{* *}$ & $0,571^{* *}$ & $0,444 *$ \\
\hline $\mathbf{N}$ & & & 1 & $-0,784 * *$ & 0,495 & $0,546^{* *}$ & $0,427^{*}$ & $0,654^{* *}$ & $0,630^{* *}$ & $0,634^{* *}$ & $0,634^{* *}$ & $0,539 * *$ & $0,629 * *$ \\
\hline$d_{g}$ & & & & 1 & $-0,394^{*}$ & $-0,433^{*}$ & $-0,250$ & $-0,413^{*}$ & $-0,385^{*}$ & $-0,374^{*}$ & $-0,321$ & $-0,256$ & $-0,401^{*}$ \\
\hline BE & & & & & 1 & $0,489^{* *}$ & $0,536 * *$ & $0,536^{* *}$ & $0,433^{*}$ & $0,581^{* *}$ & $0,557^{* *}$ & $0,506^{* *}$ & $0,589 * *$ \\
\hline Haziran YAİ & & & & & & 1 & $0,737^{* *}$ & $0,788^{* *}$ & $0,612^{* *}$ & $0,740^{* *}$ & $0,695^{* *}$ & $0,640^{* *}$ & $0,816^{* *}$ \\
\hline Temmuz YAİ & & & & & & & 1 & $0,873^{* *}$ & $0,745^{* *}$ & $0,872^{* *}$ & $0,845^{* *}$ & $0,830^{* *}$ & $0,897^{* *}$ \\
\hline Agustos YAİ & & & & & & & & 1 & $0,938^{* *}$ & $0,927^{* *}$ & $0,924^{* *}$ & $0,819^{* *}$ & $0,978 * *$ \\
\hline Eylül YAİ & & & & & & & & & 1 & $0,861^{* *}$ & $0,847^{* *}$ & $0,721^{* *}$ & $0,886^{* *}$ \\
\hline Ekim YAİ & & & & & & & & & & 1 & $0,953^{* *}$ & $0,896^{* *}$ & $0,958^{* *}$ \\
\hline Kasım YAİ & & & & & & & & & & & 1 & $0,946^{* *}$ & $0,947 * *$ \\
\hline Aralık YAİ & & & & & & & & & & & & 1 & $0,868^{* *}$ \\
\hline Ortalama YAİ & & & & & & & & & & & & & 1 \\
\hline
\end{tabular}

**: 0,01 düzeyinde anlamlı, *: 0,05 düzeyinde anlamlı 
Konuyla ilgili yapılan bazı çalışmalar incelendiğinde benzer sonuçların olduğu görülmektedir. Dantec vd. (2000) tarafında yapılan çalışmada yapraklı orman ağaçlarının oluşturduğu meşcerelerde YAİ ile N arasında pozitif yönde anlamlı ilişki bulunmuştur. Bayramoğlu ve ark. (2015) tarafından yapılan çalışmada karaçam meşcerelerinde YAİ ile bazı meşcere parametreleri arasındaki ilişkiler incelenmiştir. Çalışmadan elde edilen sonuçlar incelendiğinde bu çalışmada olduğu gibi ortalama YAİ ile V, G, N ve BE arasında pozitif yönde anlamlı ilişkiler elde edilmiştir. Khosravi vd. (2012) meşe ormanları için yaptıkları çalışmada ise YAİ ile G arasında pozitif YAİ ile meşcere orta çapı arasında negatif yönde anlamlı ilişskiler bulmuşlardır. Ercanlı vd. (2018) tarafından yapılan çalışmada ise bu çalışmaya benzer şekilde YAİ ile G ve N arasında pozitif yönde anlamlı ilişki bulunmasına rağmen bu çalışmadan farklı olarak BE ile ilgili anlamlı ilişki bulunamamıştır. Aynı çalışmada bu çalışma ile benzer şekilde meşcere orta çapı ile YAİ negatif yönde anlamlı ilişki bulunmuştur. Ayrıca bu çalışmada YAİ ile meşcere parametreleri arasındaki ilişkiler çoklu regresyon analizi kullanılarak modellenmiş ve modellerin başarı ölçütleri değerlendirilmiştir (Tablo 3). Haziran, Temmuz, Ağustos, Eylül, Ekim, Kasım ve Aralık ayları için YAİ ile meşcere parametreleri arasında yedi ve ayaların ortalama YAİ değerleri ile meşcere parametreleri arasında bir olmak üzere toplam sekiz adet regresyon denklemi (denklem 512) geliştirilmiştir.

Tablo 3. Geliştirilen modellerin performans kriterleri.

\begin{tabular}{|c|c|c|c|c|c|c|c|}
\hline \multirow[t]{2}{*}{ Parametre } & \multicolumn{3}{|c|}{ Performans kriterleri } & \multicolumn{3}{|c|}{ Sıralama yöntemi } & \multirow{2}{*}{$\begin{array}{l}\text { Siralama } \\
\text { değeri }\end{array}$} \\
\hline & $\mathbf{r}$ & $\mathbf{R}^{2}$ & HOKK & $\mathbf{r}$ & $\mathbf{R}^{2}$ & HOKK & \\
\hline YA $\dot{I}_{\text {Haziran }}$ & 0,55 & 0,30 & 0,331 & 8,000 & 8,000 & 8,000 & 24,000 \\
\hline YAİ $\dot{\mathrm{T}}_{\mathrm{Temmuz}}$ & 0,80 & 0,64 & 0,262 & 1,000 & 1,000 & 5,585 & 7,585 \\
\hline YAİ & 0,74 & 0,55 & 0,247 & 2,680 & 2,853 & 5,060 & 10,593 \\
\hline YAİ $\dot{I}_{\text {Eylül }}$ & 0,74 & 0,55 & 0,220 & 2,680 & 2,853 & 4,115 & 9,648 \\
\hline YA $\dot{I}_{\text {Ekim }}$ & 0,80 & 0,64 & 0,158 & 1,000 & 1,000 & 1,945 & 3,945 \\
\hline YAİ $\dot{I}_{\text {Kasım }}$ & 0,79 & 0,62 & 0,147 & 1,280 & 1,412 & 1,560 & 4,252 \\
\hline YAI $\dot{I}_{\text {Aralık }}$ & 0,73 & 0,53 & 0,131 & 2,960 & 3,265 & 1,000 & 7,225 \\
\hline YAİंOrtalama & 0,80 & 0,64 & 0,176 & 1,000 & 1,000 & 2,575 & 4,575 \\
\hline \multicolumn{7}{|c|}{ YA $\dot{I}_{\text {Haziran }}=0,994+(0,00041 \times \mathrm{N})$} & (5) \\
\hline \multicolumn{7}{|c|}{$\mathrm{YAI}_{\text {Temmuz }}=-1,199+(0,074 \times \mathrm{BE})+(0,102 \times \mathrm{G})-(0,007 \times \mathrm{V})-(0,001 \times \mathrm{N})$} & (6) \\
\hline \multicolumn{7}{|c|}{$\mathrm{YAI}_{\text {Ağustos }}=0,601+(0,00041 \times \mathrm{N})+(0,008 \times \mathrm{G})$} & (7) \\
\hline \multicolumn{7}{|c|}{ YA $\dot{I}_{\text {Eylül }}=0,552+(0,00035 \times \mathrm{N})+(0,008 \times$ G $)$} & (8) \\
\hline \multicolumn{7}{|c|}{ YA $\dot{I}_{\text {Ekim }}=0,459+(0,00022 \times \mathrm{N})+(0,007 \times$ G $)$} & (9) \\
\hline \multicolumn{7}{|c|}{ YA $\dot{I}_{\text {Kasım }}=0,426+(0,00031 \times N)+(0,001 \times \mathrm{V})$} & $(10)$ \\
\hline \multicolumn{7}{|c|}{ YAI $\dot{I}_{\text {Aralk }}=0,433+(0,00017 \times N)+(0,006 \times$ G $)$} & (11) \\
\hline \multicolumn{7}{|c|}{ YA $\dot{I}_{\text {Ortalama }}=-0,092+(0,031 \times G)+(0,029 \times$ BE $)-(0,002 \times \mathrm{V})$} & $(12)$ \\
\hline
\end{tabular}

Elde edilen regresyon modellerinde tüm bağımsız değişkenler anlamlıdır $(\mathrm{p}<0.05)$. En başarılı modeller Temmuz, Ekim ile ayların ortalama değerlerinin yer aldığ hataları dikkate alındığında en başarılı modelin Aralık ayına ilişkin YAİ değerlerinin kullanıldığı model olduğu görülmüştür (HOKK=0,131). Performans kriterlerine ek olarak uygulanan siralama yöntemi ile bütün kriterler dikkate alınarak model başarıları değerlendirilmiştir. Bu yöntem ile modelin en başarılı olması için en düşük sıralama ölçüt değeri aranmaktadır. Elde edilen bulgularda sıralama yöntemi ile belirlenen en başarılı model Ekim ayı için geliştirilen model olmuştur (Sıralama değeri=3,945). Bu bağlamda modellenecek değişkenlerin ölçümünün aynı ya da yakın zaman dilimlerinde yapılması model başarı sonuçlarını artırabileceği görülmüştür. Khosravi vd., (2012) meşe ormanları için meşcere parametrelerini kullanarak YAI'yi tahmin etmişlerdir. Çalışma sonucunda belirtme katsayıları $\mathrm{d}_{\mathrm{g}}$ ile $0,36, \mathrm{G}$ ile 0,36 ve meşcere orta boyu $\left(\mathrm{h}_{\mathrm{g}}\right)$ ile 0,45 elde edilmiştir. Özbayram vd. (2015) tarafından yapılan çalışmada karaçam meşcerelerinde ağaç sayısı ile $\mathrm{R}^{2}=0,90$ ve meşcere orta çapı ile $\mathrm{R}^{2}=0,66$, aynı çalışmada kızılçam meşcerelerinde ise üst boyla $\mathrm{R}^{2}=0,73, \mathrm{G}$ ile $\mathrm{R}^{2}=0,48$ ve meşcere orta çapı ile $\mathrm{R}^{2}=0,52$ düzeyinde ilişkiler bulunmuştur. Ercanlı vd. (2018) tarafından yapılan çalışmada YAİ ile meşcere parametreleri arasındaki ilişkiler çoklu regresyon ve yapay sinir ağları teknikleri ile modellenmiştir. $G, B E, N$ ve yaşın bağımsız değişken olarak yer aldığı regresyon modelinde $R^{2}=0,54$ olarak bulunmuştur. Bu çalışmada ise Haziran ve Aralık ayları hariç elde edilen regresyon modellerinin başarı düzeyleri daha yüksek bulunmuştur. Bununla birlikte Ercanlı vd. (2018) tarafından yapılan çalışmada klasik envanter ölçümleri ile birlikte YAİ değerlerine ilişkin ölçümler 2014 yılının Ağustos ayında gerçekleştirilmiştir. Ağustos ayı için elde edilen regresyon modelinin başarı düzeyi $\left(\mathrm{R}^{2}=0,54\right)$ ile bu çalışmada Ağustos ayına ilişkin elde edilen regresyon modelinin başarı düzeyi $\left(\mathrm{R}^{2}=0,55\right)$ birbirine oldukça yakın çıkmıştır. Ayrıca çalışmada her bir aya (Haziran- 
Aralık) ve ortalama YAİ'ye ilişkin geliştirilen modellerin gözlem ve tahmin grafikleri Şekil 3’te gösterilmiştir. Bulut (2021) tarafından yapılan çalışmada YAİ ile meşcere parametreleri arasındaki ilişkiler farklı modelleme teknikleri ile modellenmiştir. Çalışmada, bağımsız değişken olarak dg, N ve G modelde yer almış ve modelin başarı düzeyi $\mathrm{R}^{2}=0,55$ olarak bulunmuştur. Aynı çalışmada destek vektör makileri yöntemi YAİ ile meşcere parametreleri arasında $\mathrm{R}^{2}=0,64$ ve derin öğrenme ile $\mathrm{R}^{2}=0,72$ düzeyinde başarı bulunmuştur. Yer (2021) tarafından yapılan ve saf karaçam meşcerelerinde gerçekleştirilen çalışmada, YAİ ile meşcere parametreleri arasındaki ilişkiler araştırılmıştır. Bu çalışmada YAİ ile meşcere orta çapı arasında 0.185, üst boy ile 0.398, bonitet endeksi ile 0.265 , ağaç sayısı ile 0.334 ve göğüs yüzeyi ile 0.684 düzeyinde korelasyon ilişkileri bulunmuştur.

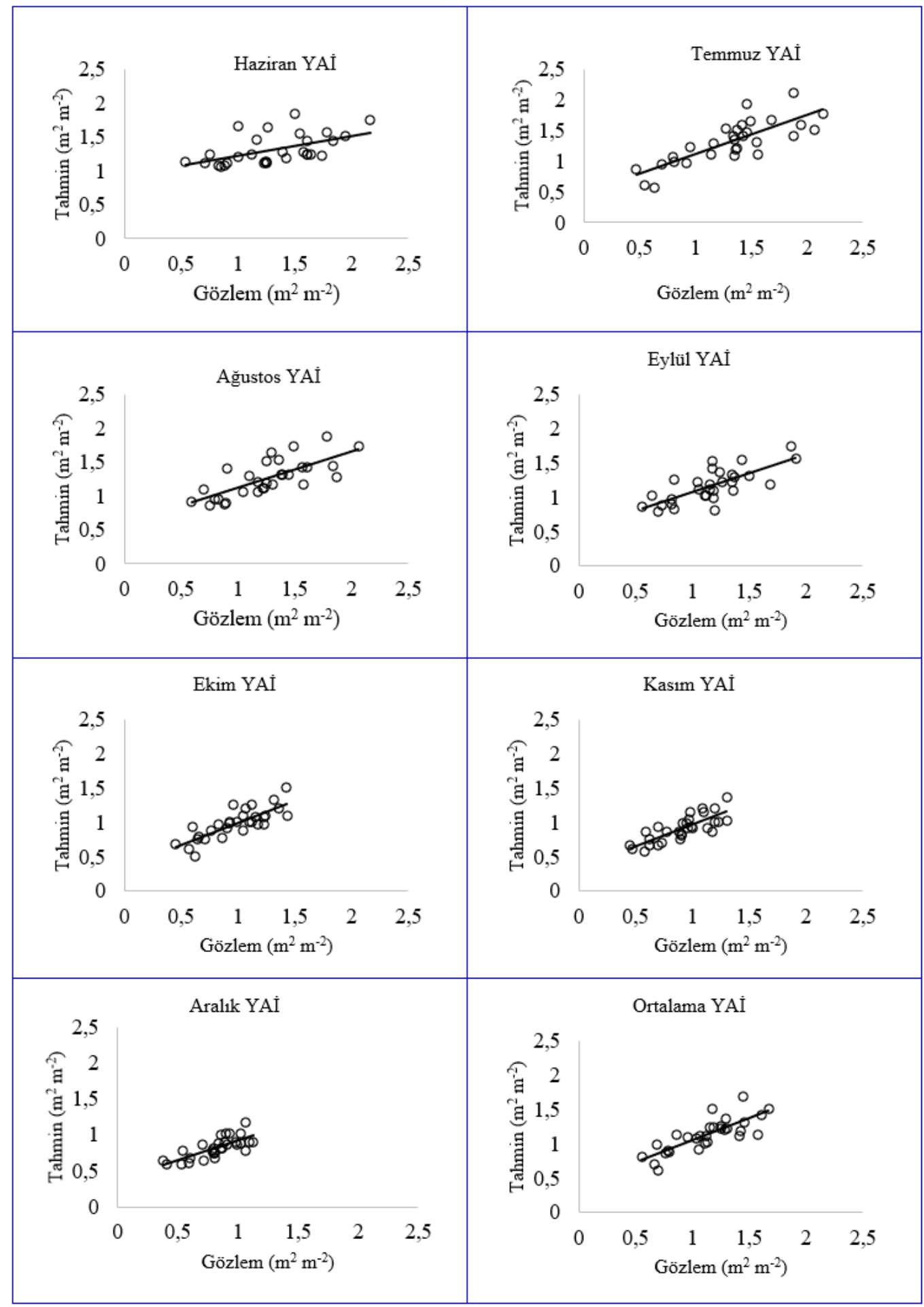

Şekil 3. Gözlem-tahmin grafikleri. 


\section{Sonuç ve Öneriler}

Bu çalışmada, yapılan korelasyon analizinde ortalama YAİ ile V, G, N ve BE arasında istatistiki olarak pozitif yönde anlamlı ilişkiler bulunmuşken, $d_{g}$ ile negatif yönde anlamlı ilişkiler bulunmuştur. Bununla birlikte her bir ay (Haziran-Aralık) için örnek alanlardan elde edilen veriler kullanılarak YAİ ile bazı meşcere parametreleri arasındaki ilişkiler çoğul regresyon analizi ile modellenmiştir. Elde edilen modellerin başarısı değerlendirildiğinde en iyi sonucun envanter ölçümlerinin yapıldığı Ekim ayında elde edildiği görülmüştür. Aylara göre elde edilen regresyon modelleri farklı orman ekosistemlerinde farklılık gösterebilir. Bu nedenle farklı orman ekosistemlerinde geliştirilecek regresyon denklemleri ile bu çalışmadan elde edilecek regresyon denklemleri karşılaştırılabilir. Bu bağlamda bu çalışmadan elde edilen sonuçlar gelecekte konuyla ilgili yapılacak çalışmalara katkı sağlayacaktır. Bununla birlikte yapılacak çalışmalarda farklı modelleme tekniklerinin kullanılması başarı düzeylerini artırabilir.

\section{Teşekkür}

Bu çalışma, Çankırı Karatekin Üniversitesi, Bilimsel Araştırma Koordinatörlüğü’nün OF080120B04 Nolu projesi tarafından desteklenmiştir.

\section{Kaynaklar}

1. Anonim (2009). Orman Genel Müdürlüğü, Yenice Orman Amenajman Planı 2009-2028. Ankara Orman Bölge Müdürlüğü, Ankara: OGM, p.435.

2. Bulut, S. (2021). Ankara Orman Bölge Müdürlüğü Saf Karaçam Meşcerelerinde Net Birincil Üretim Ve Yaprak Alan İndeksinin Uzaktan Algılama Teknikleri İle Modellenmesi. Doktora Tezi, Çankırı Karatekin Üniversitesi Fen Bilimleri Enstitüsü, Orman Mühendisliği Anabilim Dalı, Çankırı, 148 s.

3. Chen, J.M., Rich, P.M., Gower, S.T., Norman, J.M., Plummer, S. (1997). Leaf area index of boreal forests: Theory, techniques, and measurements, Journal of Geophysical Research: Atmospheres, 102(24), 29429-29443.

4. Chianucci, F., Macfarlane, C., Pisek, J., Cutini, A., Casa, R. (2015). Estimation of foliage clumping from the LAI-2000 Plant Canopy Analyzer: effect of view caps. Trees, 29(2), 355-366.

5. Dantec, V.L., Dufrene, E., Saugier, B. (2000). Interannual and spatial variation in maximum leaf area index of temperate deciduous stands, Forest Ecology and Management, 134,71-81.

6. Ercanlı, İ., Bolat, F. (2020). Ankara Orman Bölge Müdürlüğü Anadolu karaçamı meşcereleri için tek ağaç gövde çapı ve gövde hacminin uyumlu gövde çapı denklemleri ve yapay sinir ağları ile tahmin edilmesi. TÜBİTAK-TOVAG, 1190061, $105 \mathrm{~s}$

7. Ercanli, İ., Günlü, A., Şenyurt, M., Keleş, S. (2018). Artificial neural network models predicting the leaf area index: a case study in püre even-aged Crimean pine forests from Turkey, Forest Ecosystems, 529.

8. Günlü, A., Keleş, S., Ercanlı, İ., Şenyurt, M. (2017). Estimation of leaf area index using WorldView-2 and Aster satellite image: a case study from Turkey, Environmental Monitoring and Assessment, 189(11), 538.

9. Jeleska, S.D. (2004). Analysis of canopy closure in the dinaric silver fir-beech forests in Crotia using hemispherical photography, Hacquetia, 3(2),43-49.

10. Jonckheere, I., Fleck, S., Nackaerts, K., Muys, B., Coppin, P., Weiss, M., Baret, F. (2004). Review of methods for in situ leaf area index determination: Part I. Theories, sensors and hemispherical photography, Agricultural and Forest Meteorology, 121(1-2), 19-35.

11. Kara, Ö., Şentürk, M., Bolat, İ., Çakıroğlu, K. (2011). Kayın, Göknar ve Göknar-Kayın meşcerelerinde yaprak alan indeksi ile toprak özellikleri arasındaki ilişkiler, Journal of the Faculty of Forestry, Istanbul University,61(1), 47-54.

12. Khosravi, S., Namiranian, M., Ghazanfari, H., Shirvani, A. (2012). Estimation of leaf area index and assessment of its allometric equations in oak forests: northern Zagros, Iran, J Forest Sci., 58(3),116-122.

13. Madugundu, R., Nizalapur, V., Jha, C.S. (2008). Estimation of LAI and above ground biomass in decisious forests: western Ghats of Karnataka, India. Int J Appl Earth Observ Geoinform, 10,211-219. 
14. Mason, E.G., Diepstraten, M., Pinjuv, G.L., Lasserre, J.P. (2012). Comparison of direct and indirect leaf area index measurements of Pinus radiate D. Don, Agricultural and Forest Meteorology 166167, 113-119.

15. Özbayram, A.K., Çiçek, E., Yılmaz, F. (2015). Kızılçam ve Karaçam meşcerelerinde yaprak alanı indeksi (YAİ) ile bazı meşcere özellikleri arasındaki ilişkiler, Kastamonu Üni., Orman Fakültesi Dergisi, 15 (1), 78-85.

16. Poudel, K. P., Cao, Q.V. (2013). Evaluation of methods to predict Weibull parameters for characterizing diameter distributions. Forest Science, 59(2), 243-252.

17. Sidabras, N., Augustaitis, A. (2015). Application perspectives of the leaf area index (LAI) estimated by the Hemiview system in forestry. Proceedings of the Latvia University of Agriculture, p 26.

18. SPSS Institute Inc., (2007). SPSS Base 15.0 User’s Guide, 703 s.

19. Turner, D.P., Acker, S.A., Means, J.E., Garman, S.L. (2000). Assessing alternative allometric algorithms for estimating leaf area of Douglas-fir trees and stands, Forest Ecology and Management, 126, 61-76.

20. Vose, J.M., Allen, H.L. (1988). Leaf area, stemwood growth, and nutrition relationships in loblolly pine, Forest Science, 34, 547-563.

21. Yer, B.M. (2021). Kastamonu Yöresi Karaçam Meşcerelerinde Yaprak Alan İndeksi İle Çeşitli Meşcere Özellikleri Arasındaki İlişkilerin Belirlenmesi. Yüksek Lisans Tezi, Kastamonu Üniversitesi Fen Bilimleri Enstitüsü, Orman Mühendisliği Anabilim Dalı, Kastamonu, 55 s. 